\title{
Recruitment order of motor units on voluntary contraction: changes induced by proprioceptive afferent activity
}

\author{
LENNART GRIMBY AND JAN HANNERZ \\ From the Department of Neurology, Karolinska Hospital, Stockholm, Sweden
}

Knowledge of the mechanisms regulating the recruitment of individual motoneurones is essential for the understanding of normal versus pathological movements. These mechanisms have been extensively studied in animal experiments; in the decerebrate cat, for example, it has been found that the most important factor in determining the order of recruitment of motor units in reflex activity is the size of the motoneurones (Henneman, Somjen, and Carpenter, 1965a, b; Somjen, Carpenter, and Henneman, 1965). But very little is known about their recruitment by voluntary effort in the intact human organism. It has been established that the sequence of recruitment during voluntary muscle contraction varies (Seyffarth, 1940; Harrison and Mortensen, 1962), and different theories have been proposed to explain this. It has been found that different units are engaged in different muscular functions (Seyffarth, 1940). It has been proposed that a direct selective cerebral control over single anterior horn cells exists (Basmajian, 1963). The position of the extremity under study during initiation of a voluntary contraction has also been shown to play a role (Wagman, Pierce, and Burger, 1965).

In a previous paper (Ashworth, Grimby, and Kugelberg, 1967) it was shown that motor units are usually recruited in the same order, whether they are activated by voluntary effort or through proprioceptive or nociceptive reflex arcs. It could, however, also be established that the pattern of motor unit recruitment changed in the course of an experiment so that the unit first recruited by one of these three routes of activation alternated with a couple of other units of nearby thresholds.

The present paper gives an account of a series of experiments designed to find out the cause of these variations, and particularly the role played by proprioceptive facilitation and the gamma loop (Leksell, 1945).
METHODS

The muscle tested was the anterior tibial muscle. Most of the experiments were performed on ourselves but the validity of the results was confirmed in control experiments on other subjects.

The motor unit potentials were recorded with bipolar needle electrodes (Disa no. 9013K0802), which have previously been shown to have a selectivity neither too high nor too low for experiments of this type and which can pick up responses from 10 to 20 units in the anterior tibial muscle (Ashworth et al., 1967). The potentials were amplified and displayed on two oscilloscopesnamely a standard oscilloscope with continuous sweep and a Tektronix storage oscilloscope no. 564 which was triggered by the first positive deflection of the first potential in each sequence. All experiments were recorded on tape and the results obtained were confirmed by repeated play-backs and by film recordings of the principal parts.

The subject's foot was fixed in the normal position by straps. To avoid displacements of the recording electrodes in the course of the experiment, only the initial phase of the voluntary contraction was studied.

Mechanical vibration of the muscle tendon was applied by means of a commercial massage apparatus (Relax) with a vibration frequency of $100 / \mathrm{sec}$ and a vibration intensity shown to be sufficient to induce a reflex contraction (Hagbarth and Eklund, 1966).

Conclusions were drawn exclusively from recordings in which all activated units displayed characteristic potentials which remained unchanged throughout the experiment and which did not interfere with one another. Only part of the recordings met these criteria; however, recordings from more than 1,000 different needle positions resulted in more than 200 technically incontestable recordings.

\section{RESULTS}

A very sudden contraction tended to be initiated by one unit but to be continued by another (Figs. 1 and 2). Such a 'rotation' occurred in about every second recording if the muscle had been relaxed for some minutes, but was only rarely seen if the muscle 


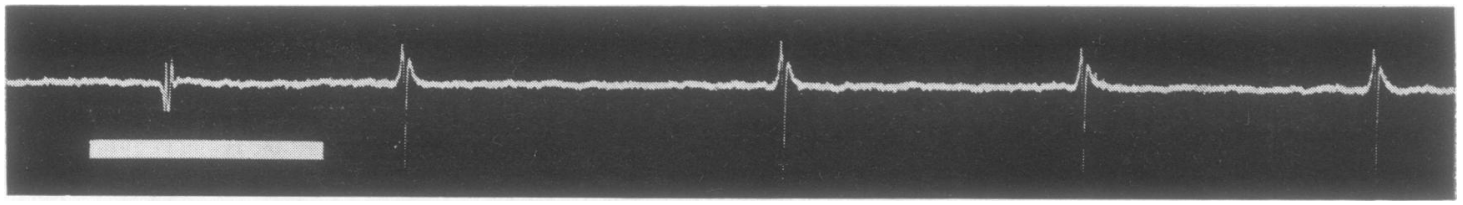

FIG. 1. Rapid initiation of contraction: rotation from A to B unit. Time bar 100 msec.

was not completely relaxed when the contraction was initiated or had been active immediately before the contraction (cf. below). This rotation has not been observed previously, probably because previous analyses have not been made on completely relaxed muscle.

The unit first activated (below called the A unit) usually discharged only once or twice (Fig. 1) but could respond with brief bursts during strong twitches (Fig. 2). Two or three different units in each unit population could alternate as $\mathbf{A}$ unit. Whether the one or the other was recruited seemed to be a matter of chance but might depend on the velocity of the initiation of the contraction.

The unit activated second in the series (below called the B unit) then dominated the activity. In a unit population, one and the same unit almost invariably represented the $B$ unit. On gentle contraction the activity was both initiated and continued by the $B$ unit. This was the case also when an initial subliminal voluntary facilitation of the muscle was followed by a rapid contraction.

The B unit continued to discharge alone as long as the contraction was maintained at threshold level, but when it was increased and more units recruited, still another unit of nearby threshold (below called the $\mathrm{C}$ unit) tended to predominate (Fig. 3). A 'rotation'-namely, a completed change of threshold unit-resulted on increased contraction in about one out of 10 recordings. In exceptional cases the B unit dropped out, leaving the $\mathrm{C}$ unit alone in spite of the increased contraction. As a rule, however, both units were active on strong contraction and the $\mathrm{C}$ unit alone only when the contraction had been reduced (Fig. 3).

DISCHARGE PATTERN OF THE UNITS Tokizane and coworkers (see Tokizane and Shimazu, 1964) have found two functionally different types of motor units in man. One of them (called tonic) sets up regular discharges even at such a low frequency as $8 / \mathrm{sec}$ and mediates sustained activity. The other type of unit (called kinetic) maintains a constant discharge only at frequencies exceeding $15 / \mathrm{sec}$ and responds-for example, to twitch.

When the $A, B$, and $C$ units were analysed in the manner described by Tokizane and Shimazu (1964) the group of $\mathrm{A}$ units was found to be heterogeneous? Some of them set up a regular low-frequency activity on strong sustained contraction, but some $A$ unit responded only after rapid increase of the contrac? tion strength, and then in the shape of irregulav high-frequency bursts. The B units, on the othej. hand, invariably discharged regularly at a frequency $\overrightarrow{0}$ exceeding 10/sec. The $\mathrm{C}$ units had a still more constant discharge pattern and responded at regular intervals down to a frequency of $6 / \mathrm{sec}$.

Since the responses of the $A$ units are of too short duration to permit a systematic study of the rotation between $\mathrm{A}$ and $\mathrm{B}$ units, the present analysis

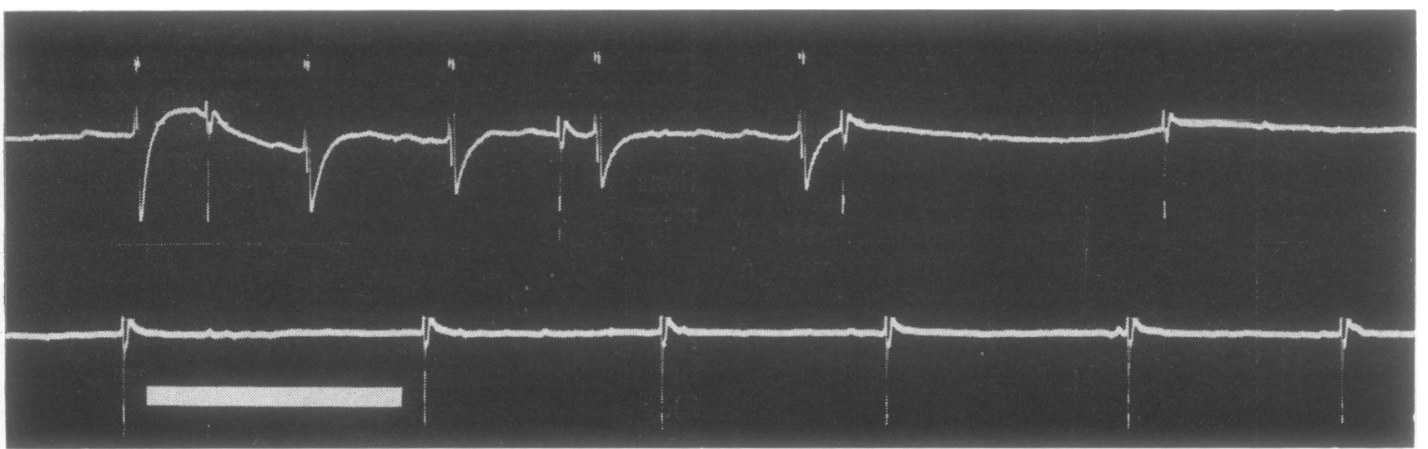

FIG. 2. Strong twitch followed by maintained contraction: rotation from A to B unit. Time bar 100 msec. 


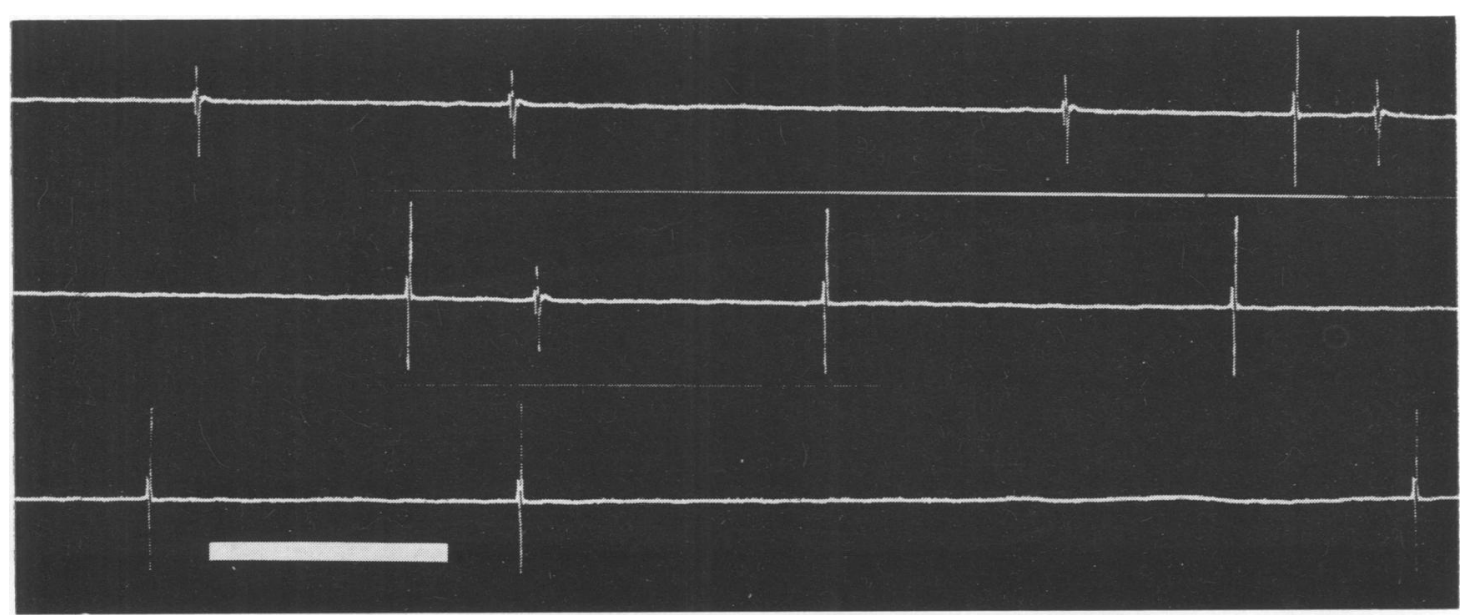

FIG. 3. Maintained isometric contraction: rotation from B to C unit. Time bar 100 msec.

will in the following be limited to the rotation of the $B$ and $C$ units.

EFFECTS OF RESISTANCE TO CONTRACTION When the foot is fixed in the normal position a contraction of the anterior tibial muscle is mainly isotonic until the tendon is stretched and then becomes mainly isometric. The change from $\mathrm{B}$ to $\mathrm{C}$ unit dominance roughly coincided with the transition from isotonic to isometric contraction. This transition is accompained by increased activity both of the facilitatory muscle spindle afferents and of the inhibitory Golgi afferents (Matthews, 1933). It was thus considered to be pertinent to study systematically the effects obtained when a resistance was applied to a contraction of the anterior tibial muscle, using pairs of units in which rotation could easily be achieved.

The main effect of stretch of an active muscle is a facilitation (Hoffmann, 1922; Hufschmidt, 1961), very likely caused by increased afferent activity of the muscle spindles (Hunt and Kuffler, 1951a, b). When a strong resistance was suddenly introduced during an isotonic contraction of the anterior tibial muscle dominated by a $\mathbf{B}$ unit, this unit was substituted by the $C$ unit as number one unit (Fig. 4:1). When the contraction was initiated just when stretch was applied to the muscle by the operator, the $C$ unit started the activity (Fig. 4:2); this never happened unless stretch was applied.

The main effect of unloading a muscle is an inhibition (Hoffmann, 1922; Hufschmidt, 1961), very likely caused by a decreased excitatory influence from the muscle spindles (Struppler, Landau, and Mehls, 1964). When the resistance was suddenly removed during a contraction of the anterior tibial muscle dominated by the $C$ unit, the $B$ unit resumed its previous dominant role (Fig. 4:3). When the contraction was initiated as the operator unloaded the muscle the B unit could attain a very high frequency without the $C$ unit being activated (Fig. 4:4).

The rotation between different units thus described could never be brought about nor prevented by a voluntary effort on the part of the subject.

VIBRATION OF THE MUSCLE TENDON In animal experiments, Granit and Henatsch (1956) have shown that primary spinal endings are very sensitive to vibration. Hagbarth and Eklund (1966) and De Gail, Lance, and Neilson (1966) have induced tonic reflex contractions in man by mechanical vibration of various muscle tendons in the extremities at a frequency of 100 to $400 / \mathrm{sec}$. They assumed that this tonic reflex is elicited mainly through $1 \mathrm{a}$ afferents and presented strong reasons for this assumption.

In the present series of experiments, the effect of this artificial afferent activity on the recruitment order was studied using pairs of units in which rotation could easily be achieved.

Before vibration was applied to the tendon of the anterior tibial muscle, and also after it had been applied for about 5 seconds, voluntary initiation of a contraction resulted in B unit activity (Fig. 5: 1). But when it had been applied for 10 to 15 seconds, voluntary initiation of contraction resulted in C unit activity (Fig. 5: 2). On cessation of the vibration in the course of this $\mathrm{C}$ unit activity, the B unit once more became dominant (Fig. 5: 3).

When strong vibration had been applied for 20 to 30 seconds, an activity might set in which the subject perceived as involuntary; this is in accord with the 

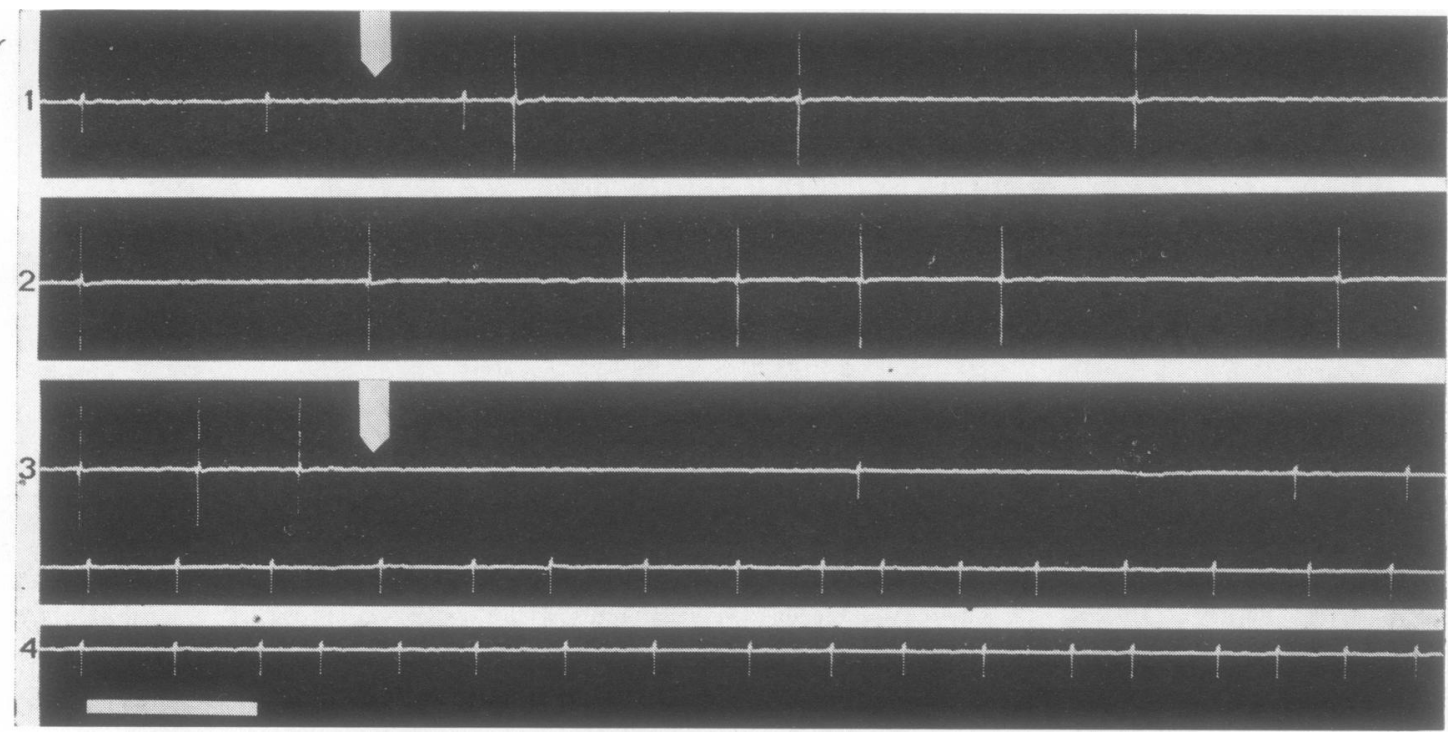

FIG. 4. (1) Sudden resistance applied to contraction (at arrow): rotation from B to C unit. (2) Initiation of contraction on passive stretch of the muscle: isolated $C$ unit activity. (3) Sudden unloading of the muscle (resistance removed at $\dot{ }$. arrow): $C$ unit substituted by $B$ unit. (4) Initiation of contraction on unloading of the muscle: isolated high-frequency Bo $O$ unit activity. Time bar 100 msec.
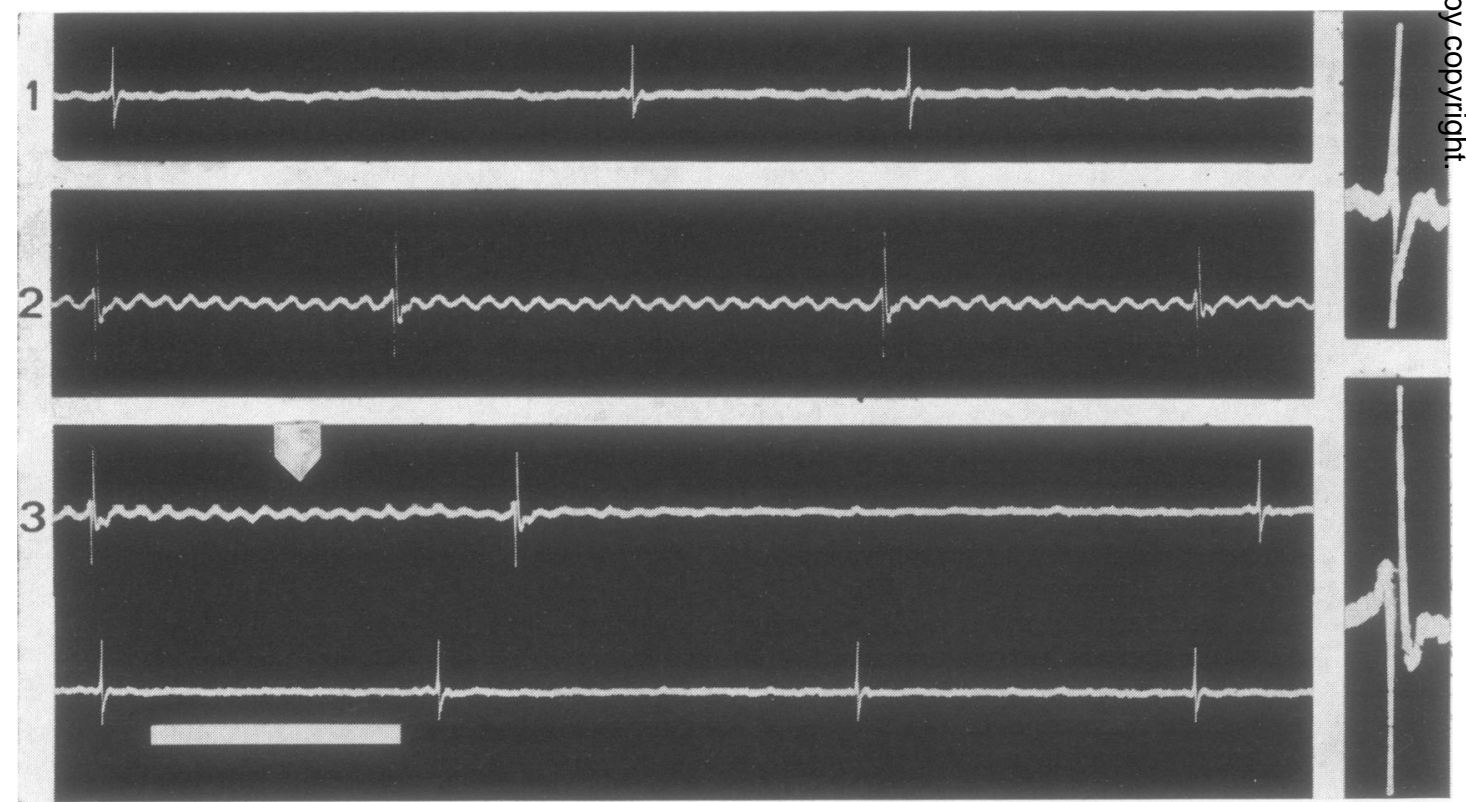

FIG. 5. Effects of vibration of the muscle tendon. (1) Voluntary contraction initiated before vibration: isolated B unit activity. (2) Voluntary contraction initiated after $15 \mathrm{sec}$ vibration: isolated $C$ unit activity. (3) Cessation of vibration (vibrator removed at arrow): $C$ unit substituted by $B$ unit. Time bar 100 msec. To the right: shape of $B$ and $C$ units in magnification. 
description given by Hagbarth and Eklund (1966). This activity was initiated and dominated by the $\mathrm{C}$ unit.

$\mathrm{C}$ unit activity never started a contraction unless vibration had been applied.

NERVE BLOCKING WITH LIDOCAINE If the facilitation of the $\mathrm{C}$ unit to number one unit depends upon proprioceptive afferent activity, then it ought to be possible to re-establish the dominant role of the $\mathrm{B}$ unit by blocking the afferent impulses. The proprioceptive facilitation is reduced by injections of local anaesthetics into a muscle nerve without it being necessary to eliminate the activity of the alpha motoneurones (for example, Gasser and Erlanger, 1929; Leksell, 1945). Most authors are of the opinion that this is due to blocking of the gamma motoneurones (for example, Matthews and Rushworth, 1957), but blocking of the muscle afferents has also been shown to play a role (Gassel and Diamantopoulos, 1964).

When, during isometric contraction, the B unit had been substituted by the $C$ unit as number one unit, a trained subject could maintain a pure and regular $\mathrm{C}$ unit activity for about $\mathbf{1 0}$ minutes. In one experiment, when a stable activity of this type had been achieved, $1 \%$ lidocaine was injected around the distal part of the motor nerve. After a few minutes the $\mathrm{C}$ unit then began to discharge irregularly which according to, for example, Tokizane and Shimazu (1964) is an indication of reduced proprioceptive afferent activity. The $C$ unit was soon substituted by the $B$ unit as dominant unit but could still be activated and was thus not itself blocked.

SIMULTANEOUS CONTRACTION OF THE ANTERIOR TIBIAL AND OTHER LOWER LEG MUSCLES From animal experiments it is known that the motoneurone excitability in a muscle is influenced by proprioceptive afferent impulses from synergistic and antagonistic muscles (Eccles, Eccles, and Lundberg, 1957). Also other feedback mechanisms have been shown to have a similar effect; thus, for example, Renshaw collaterals may exert both a facilitatory and an inhibitory action on the alpha motoneurones of a synergistic muscle (Renshaw, 1941).

In the present study it was found that the recruitment order of the units in the anterior tibial muscle changed on contraction of another lower leg muscle, whereas no such effect was seen on contraction of proximal or contralateral muscle groups and on Jendrassik's manoeuvre. During 'co-contraction' of the anterior tibial muscle and other lower leg muscles in various combinations, a trained subject could achieve rotation in every recording as against only one out of 10 recordings when the anterior tibial muscle was contracted alone.

The facilitation of the $\mathrm{C}$ unit to number one unit could be achieved faster and more infallibly during co-contraction than on isolated contraction of the anterior tibial muscle. The effect of co-contraction was thus similar to that produced by stretch or vibration of the tendon.

In experiments in which the B unit invariably started an isolated contraction of the anterior tibial muscle, the $\mathrm{C}$ unit was often recruited first when other lower leg muscles were active before the contraction of the anterior tibial muscle. Sometimes this result was also obtained on relaxation of the other muscles immediately before the contraction of the anterior tibial muscle.

During co-contraction also other units than the A, B, or C units could become the unit of lowest threshold. This is in accord with Seyffarth's (1940) observation that the units recruited in a muscle may differ depending on what synergists the muscle is acting in concert with.

Harrison and Mortensen (1962) have shown that it is possible for trained subjects with the help of auditory cues to single out up to six different units out of the large unit population recorded by surface electrodes. This observation has been confirmed by other authors, among them Basmajian (1963) who has taken it as an indication of a direct selective cerebral control over individual anterior horn cells.

In our experiments, the subject never succeeded in recruiting other units than $A$ and $B$ as the number one unit if other muscles of the lower leg had to be relaxed for a minute before the contraction of the anterior tibial muscle. But if he was allowed to contract the other muscles in advance he could always initiate the contraction of the anterior tibial muscle also with other units.

If the subject fixed his ankle joint in the normal position by voluntary effort, the operator could single out various units at discretion by twisting and pulling at the leg in various directions, without any other co-operation on the part of the subject than his keeping the ankle joint fixed.

RESTITUTION OF THE ORIGINAL RECRUITMENT ORDER If a contraction was stopped when the $B$ unit had been substituted by the $C$ unit and then immediately taken up again, the $\mathrm{C}$ unit remained dominant, but after a period of muscle relaxation the $B$ unit was once more recruited as the unit number one. The delay required before the original recruitment pattern was re-established was related to the duration and intensity of the $C$ unit activity during the preceding contraction. Thus, if the contraction was stopped as soon as the $\mathrm{C}$ unit had become active 
the original recruitment order was again obtained within a second (cf. Figs. 4 and 5), but if the $C$ unit had been dominant for several minutes, more than a minute might elapse before the contraction was again initiated by the $B$ unit.

Passive dorsiflexion of the foot accelerated the restitution of the original recruitment order but it could still take more than 10 seconds before the $B$ unit was re-established as the number one unit.

Isolated contraction of a synergist of the anterior tibial muscle delayed the restitution, but contraction of the triceps surae occasionally accelerated it. Contraction of muscles outside the lower leg, or Jendrassik's manoeuvre, had no visible effect on the time required for the restitution of the original pattern.

The time required to re-establish the original recruitment order after a rotation from $B$ to $C$ units induced by vibration never exceeded $10 \mathrm{sec}-$ onds and was thus considerably shorter than the delay required after a rotation induced by isometric contraction.
At the moment when the B unit was coming back as the number one unit, this unit was recruited first on abrupt contraction but the $\mathrm{C}$ unit on slow contraction. After a further period of rest the contraction was invariably initiated by the $B$ unit but when this unit had discharged once or twice it was substituted by the $C$ unit as number one unit (Fig. 6: 2). The longer the subsequent period of rest, the longer was the delay in the rotation from B to C unit activity (Fig. 6: 3), and finally isolated $B$ unit activity could be maintained for many minutes (Fig. 6: 4), isolated $C$ unit activity being then achieved only by means of stretch or vibration of the tendon of the anterior tibial muscle. Thus, the B unit was here of the same phasic character as is typical of the A unit (cf. Figs. 1 and 2).

\section{DISCUSSION}

On voluntary initiation of a contraction the recruitment order of the units may differ depending on the velocity of the initiation, one unit being activate
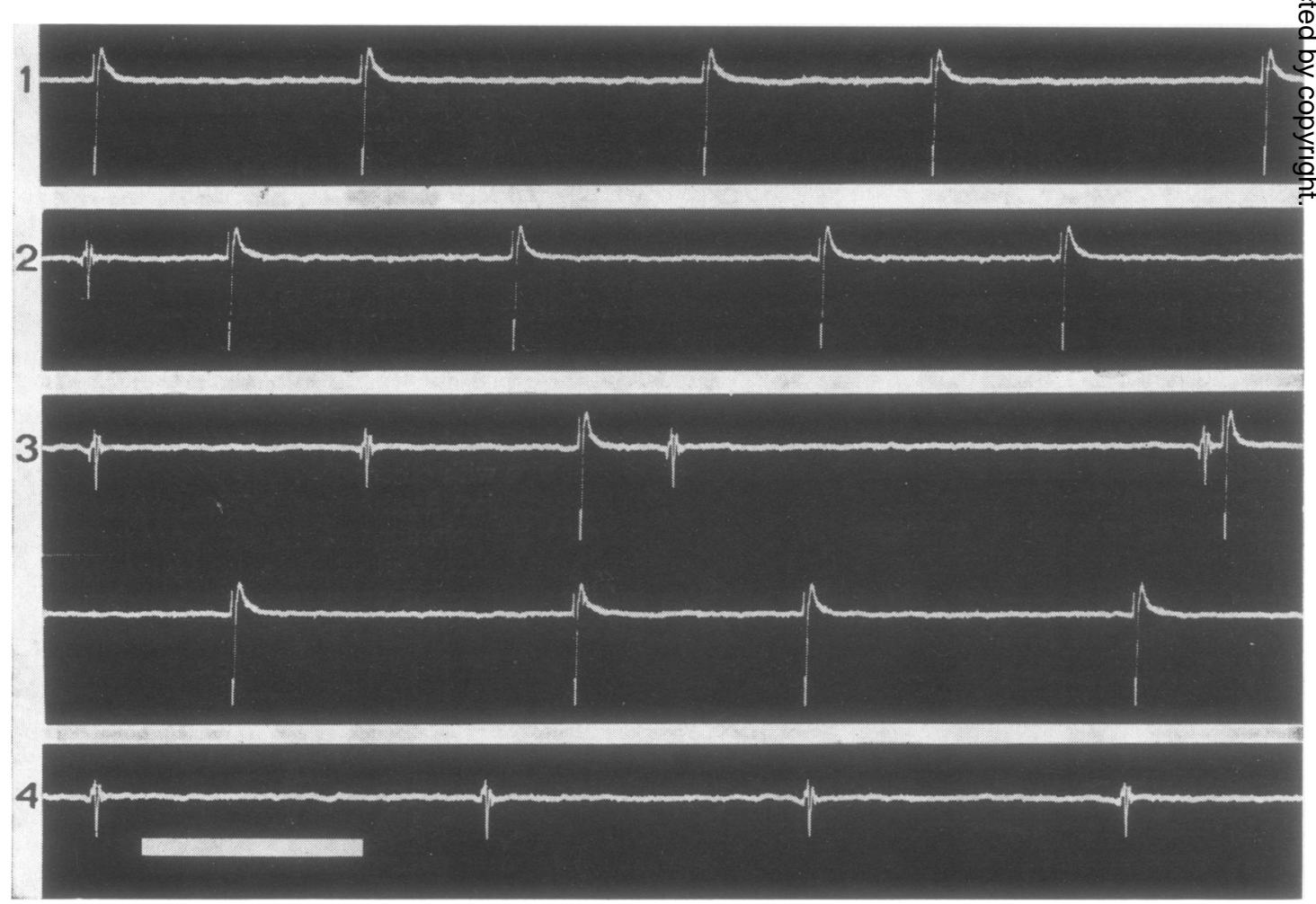

FIG. 6. Restitution of original recruitment order after relaxation of a contraction during which the recruitment order was changed. (1) Contraction initiated after $5 \mathrm{sec}$ relaxation: still isolated $C$ unit activity. (2) Contraction initiated after $15 \mathrm{sec}$ relaxation: rapid rotation from $B$ to $C$ unit. (3) Contraction initiated after 30 sec relaxation: slower rotation from $B$ to $C$ unit. (4) Contraction initiated after $60 \mathrm{sec}$ relaxation: isolated B unit activity. Time bar 100 msec. 
first on slow, and another on rapid initiation. But this difference is eliminated when the state of facilitation of one of the units is altered, whether it be increased or reduced (cf. Fig. 6). Also, a unit which in a given situation is favoured by rapid initiation of contraction may in another situation be favoured by slow initiation (cf. the behaviour of the B unit in Figs. 2 and 6). Hence it seems as though the different recruitment order on slow and rapid initiation is governed not only by the inherent properties of the units but by their state of facilitation.

The alpha motoneurone can be activated voluntarily either directly or indirectly, through the gamma loop. It is generally agreed that the direct route of activation predominates only on very rapid contractions and that in other cases facilitation through the gamma loop is decisive (see Granit, 1957). Tokizane and Shimazu (1964) have shown that the regularity in discharge rate of a unit on voluntary contraction depends upon the strength of its afferent input. In the present experiments, the tendency to regular discharges was more pronounced in the unit favoured by slow initiation. It is thus reasonable to assume that the different recruitment order on rapid and slow initiation of contraction is associated with the difference in gamma loop involvement.

During sustained contraction there may be a new shift of number one unit, but without a fairly longlasting contraction the subject cannot provoke such a shift. The threshold changes are thus correlated to the contraction. The order of recruitment of two units may vary without preceding activation of either of them. The threshold variations cannot thus be attributed to fatigue; they can probably best be explained in terms of a feedback effect.

The various experiments described above strongly indicate that the proprioceptive afferents, particularly from spindles, play a major role in the threshold changes. But this of course, does not exclude involvement of other factors; the remarkably strong effect of simultaneous contraction of synergists may point in this direction.

Changes in recruitment order on changes in the proprioceptive afferent activity occurred mainly in units of nearby thresholds. This is in agreement with the concept previously advanced (Ashworth et al., 1967) that inherent properties of the motoneurone are the most important factor in determining the order of recruitment of motor units.

In animal experiments it has been found that elimination of the gamma loop results in a general rise in threshold (Leksell, 1945) but retained order of recruitment of the units (Henneman et al., 1965a). Henneman and co-workers considered the sequence of recruitment to be dependent exclusively on the size of the motoneurone cells. This is in contrast to our findings, and as a matter of fact the concept of a hierarchy of motor units entirely dependent on the size of the cells and thus completely stereotyped has not been borne out by the results obtained in most human experiments.

The discrepancy between Henneman's results and ours may be due to the different experimental subjects used. Henneman's experiments were performed on decerebrate and partly de-efferented cats in which the gamma innervation may be stereotyped as compared with that in intact man. Another explanation may be the different sensitivity of the methods used. Henneman studied root filaments containing 2-5 nerve fibres, whereas we studied populations of 10-20 units, and the chances of recording variations in the order of appearance of units of nearby thresholds are of course greater the larger the unit population studied.

The muscle has to be completely relaxed for a minute or more before the original recruitment is with certainty re-established. The delay may in part be due to post-excitatory facilitation of the muscle spindles (Kuffler, Hunt, and Quilliam, 1951), but the fact that the state of facilitation may sometimes be sustained over a minute suggests that central mechanisms may be involved. From animal (Lloyd, 1949) as well as from human experiments (Hagbarth, 1962; Blom, Hagbarth, and Skoglund, 1964) it is known that there exists post-tetanic potentiation in the monosynaptic path of the muscular afferents upon ventral horn cells which may last for minutes. According to Granit (1956), the normal discharge frequency of the afferents is high enough to set up such a post-tetanic potentiation. Even after a rotation, the recruitment order is the same on voluntary contraction as on a proprioceptive or nociceptive reflex (Ashworth et al., 1967). The long-lasting facilitation is thus more important for the recruitment order than is the way of activation.

Granit (1957) defines tonic units as units which maintain long-lasting concealed states of facilitation. This definition applies at least to the $B$ and $C$ units. According to Tokizane and Shimazu (1964), a characteristic feature of a tonic unit is its ability to maintain a regular low-frequency activity. Some A units and all B and C units meet this criterion. But the different groups of units have different properties, and in this respect they differ from Tokizane's tonic group which he considered to be entirely homogeneous. With the exception of very rapid initiations of contractions in completely relaxed muscle it seems as though only tonic units are active on weak contraction of the anterior tibial muscle. There may be different explanations 
for this. Thus, tonic motoneurones are smaller than phasic (Granit, Henatsch and Steg, 1956) and hence more readily activated (Henneman et al., 1965a); further, there is a comparatively large number of tonic units in the anterior tibial muscle (Kawakami, 1954); and finally, the tonic units can maintain long-lasting states of facilitation more readily than the phasic units.

However, some A units have the same properties as the kinetic units described by Tokizane and Shimazu (1964). These units were activated only on rapid initiation of contraction and were soon substituted by tonic units (cf. Figs. 1 and 2). Phasic units consist exclusively of white muscle fibres, and tonic units exclusively of red fibres (Edström and Kugelberg, 1968). If the white fibres are driven to constant activity by electrical nerve stimulation at a frequency of $5 / \mathrm{sec}$ they are silenced after 5 minutes (Kugelberg and Edström, 1968). Under normal conditions the phasic units must thus be protected against long-lasting constant activity. One defence mechanism may be that the tonic units of the muscle become facilitated by the contraction and thus recruited instead of the phasic units, as is illustrated in Figs. 1 and 2.

Impairments of proprioceptive functions are essential factors in the development of spasticity, at least in some types of rigidity, and the findings reported above should thus have clinical implications. A corresponding analysis of the recruitment of motor units in patients with different types of motor disorders is also in progress.

\section{SUMMARY}

The recruitment order of motor units on voluntary contraction of the anterior tibial muscle was studied in normal human subjects, using electrodes recording from 10 to 20 units.

1. The recruitment order of the units differed depending on the velocity of the contraction. A rapid contraction of a completely relaxed muscle was started by one unit setting up only a few discharges (called A) and continued by a constantly discharging unit (called B) in about half the recordings. A slow contraction or a contraction of a muscle that was not completely relaxed was started directly by the B unit.

2. During sustained isometric contraction the $B$ unit was substituted by still another unit (called C) in about every tenth recording. The same shift was produced by passive stretch of the muscle and by mechanical vibration of its tendon. The original recruitment order was re-established by unloading the muscle and-in one experiment-by partial blocking of the muscle nerve with lidocaine.
3. Contraction of other lower leg muscles could facilitate the $C$ unit to number one unit but could also facilitate new units (other than A, B, and C). 4. After relaxation of a contraction during which the recruitment order was changed, the original recruitment order was re-established, but only after a delay sometimes exceeding a minute.

The conclusion was drawn that the recruitment order of motor units on voluntary contraction is altered by proprioceptive afferent activity producing a facilitation of varying strength in different tonic units.

\section{REFERENCES}

Ashworth, B., Grimby, L., and Kugelberg, E. (1967). Comparison of voluntary and reflex activation of motor units. J. Neurol. Neurosurg. Psychiat., 30, 91-98.

Basmajian, J. V. (1963). Control and training of individual motor units. Science, 141, 440-441.

Blom, S., Hagbarth, K. E., and Skoglund, S. (1964). Post-tetanic potentiation of $\mathrm{H}$-reflexes in human infants. Exp. Neurol., 9, 198-211.

De Gail, P., Lance, J. W., and Neilson, P. D. (1966). Differential effects on tonic and phasic reflex mechanisms produced by vibration of muscles in man. J. Neurol. Neurosurg. Psychiat., 29, 1-11.

Eccles, J. C., Eccles, R. M., and Lundberg, A. (1957). The convergence of monosynaptic excitatory afferents on to many different species of alpha motoneurones. J. Physiol. (Lond.), 137 $22-50$.

Edström, L., and Kugelberg, E. (1968). Histochemical composition distribution of fibres and fatigability of single motor units J. Neurol. Neurosurg. Psychiat., 31, 424-433.

Gassel, M. M., and Diamantopoulos, E. (1964). The effect of procain nerve block on neuromuscular reflex regulation in man. AB appraisal of the role of the fusimotor system. Brain, $8 \%$ 729-742.

Gasser, H. S., and Erlanger, J. (1929). The role of fiber size in the establishment of a nerve block by pressure or cocaine. Amers J. Physiol., 88, 581-591.

Granit, R. (1956). Reflex rebound by post-tetanic potentiation Temporal summation-spasticity. J. Physiol. (Lond.), 131, 32-5F.

Granit, R. (1957). Systems for Control of Movement. Ier congr. internat. sci. neurol. Bruxelles 1957. Pp. 63-80.

Granit, R., and Henatsch, H. D. (1956). Gamma control of dynamic properties of muscle spindles. $J$. Neurophysiol., 19, 356-366.

Granit, R., Henatsch, H. D., and Steg, G. (1956). Tonic and phasic ventral horn cells differentiated by post-tetanic potentiation in cat extensors. Acta. physiol scand., 37, 114-126.

Hagbarth, K. E. (1962). Post-tetanic potentiation of myotatic reflexes in man. J. Neurol. Neurosurg. Psychiat., 25, 1-10.

Hagbarth, K. E., and Eklund, G. (1966). Motor effects of vibratory muscle stimuli in man, pp. 177-186. In Proceedings of the First Nobel Symposium, 'Muscular Afferents and Motor Control', ed. by R. Granit, Almqvist and Wiksell, Stockholm.

Harrison, V. F., and Mortensen, O. A. (1962). Identification and voluntary control of single motor unit activity in the tibialis anterior muscle. Anat. Rec., 144, 109-116.

Henneman, E., Somjen, G., and Carpenter, D. O. (1965a). Functional significance of cell size in spinal motorneurons. J. Neurophysiol, 28, 560-580.

Henneman, E., Somjen, G., and Carpenter, D. O. (1965b). Excitability and inhibitibility of motorneurons of different sizes. J. Neurophysiol. 28, 599-620.

Hoffman, P. (1922). Untersuchungen über die Eigenreflexe menschlicher Muskeln. Springer, Berlin.

Hufschmidt, H. J. (1961). Bausteine motorischer Regelung. Schweiz. Arch. Neurol. Psychiat., 87, 260-280.

Hunt, C. C., and Kuffler, S. W. (1951a). Further study of efferent small-nerve fibres to mammalian muscle spindles. Multiple spindle innervation and activity during contraction. J. Physiol. (Lond.), 113, 283-297.

Hunt, C. C., and Kuffler, S. W. (1951b). Stretch receptor discharges during muscle contraction. J. Physiol. (Lond.), 113, 298-315. 
Kawakami, M. (1954). Electromyographic study on the functional differentiation of the hand and foot muscles. Jap. J. Physiol., 4, 1-6.

Kuffler, S. W., Hunt, C. C., and Quilliam, J. P. (1951). Function of medullated small-nerve fibres in mammalian ventral roots: efferent muscle spindle innervation. J. Neurophysiol., 14, 29-54.

Kugelberg, E., and Edström, L. (1968). Differential histochemical effects of muscle contractions on phosphorylase and glycogen in various types of fibres. J. Neurol. Neurosurg. Psychiat., 31, 415-423.

Leksell, L. (1945). The action potential and excitatory effects of the small ventral root fibres to skeletal muscle. Acta physiol. scand., 10 (Suppl. No. 31), 1-84.

Lloyd, D. P. C. (1949). Post-tetanic potentiation of response in monosynaptic reflex pathways of the spinal cord. J. gen. Physiol., $33,147-170$.

Matthews. B. H. C. (1933). Nerve endings in mammalian muscle. $J$. Physiol. (Lond.), 78, 1-53.
Matthews, P. B. C., and Rushworth, G. (1957). The selective effect of procaine on the stretch reflex and tendon jerk of soleus muscle when applied to its nerve. J. Physiol. (Lond.), 135, 245-262.

Renshaw, B. (1941). Influence of discharge of motorneurons upon excitation of neighboring motorneurons. J. Neurophysiol., 4, 167-183.

Seyffarth, H. (1940). The behaviour of motor units in voluntary contraction. Skr. norske Vidensk. -Akad. I. Mat.-nat. Kl., No. 4.

Somjen, G., Carpenter, D. O., and Henneman, E. (1965). Responses of motorneurons of different sizes to graded stimulation of supraspinal centers of the brain. J. Neurophysiol., 28, 958-965.

Struppler, A., Landau, W. M., and Mehls, H. (1964). Analyse des Entlastungsreflexes (ER) am Menschen. Pfügers. Arch. ges. Physiol., 279, R18-R19.

Tokizane, T., and Shimazu, H. (1964). Functional Differentiation of Human Skeletal Muscle, pp. 1-62. University of Tokyo Press, Tokyo.

Wagman, I. H., Pierce, D. S., and Burger, R. E. (1965). Proprioceptive influence in volitional control of individual motor units. Nature (Lond.), 207, 957-958. 